Portland State University

PDXScholar

5-1974

\title{
An exporatory study of depression in adolescents placed in residential treatment centers
}

Shirley D. Hale

Portland State University

Kermit C. Jeffrey

Portland State University

Gerald J. Moneke

Portland State University

Follow this and additional works at: https://pdxscholar.library.pdx.edu/open_access_etds

Part of the Psychiatric and Mental Health Commons, and the Social Work Commons Let us know how access to this document benefits you.

\section{Recommended Citation}

Hale, Shirley D.; Jeffrey, Kermit C.; and Moneke, Gerald J., "An exporatory study of depression in adolescents placed in residential treatment centers" (1974). Dissertations and Theses. Paper 1745. https://doi.org/10.15760/etd.1744

This Thesis is brought to you for free and open access. It has been accepted for inclusion in Dissertations and Theses by an authorized administrator of PDXScholar. Please contact us if we can make this document more accessible: pdxscholar@pdx.edu. 
AN EXPLORATORY STUTY OF DEPRESSION IN ADOLESCENTS PLACED IN RESIDENTIAL TREATMENT CENTERS

by

SHIRLEY D. HALE, KERMII C, JEFFREY, and

GERALD J. MONEKE

A report submitted in partial fulfillment of the requirements for the degree of

MASTER OF SOCIAL WORK

Portland State University 1974 


\section{This Practicum for the \\ Master of Social Work Degree}

\section{By}

Shirley D. Hale, Kermit C. Jeffrey,

and

Gerald J. Moneke

has been approved

$$
\text { May, } 1974
$$

Chairman, Practicum Committee

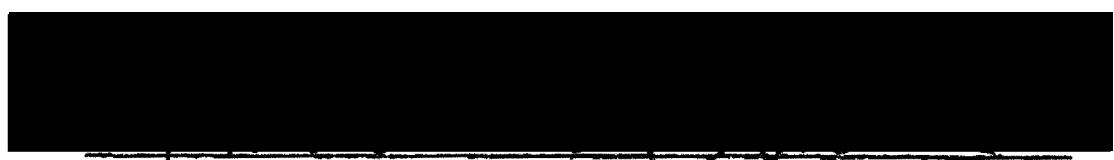

Compittee Member

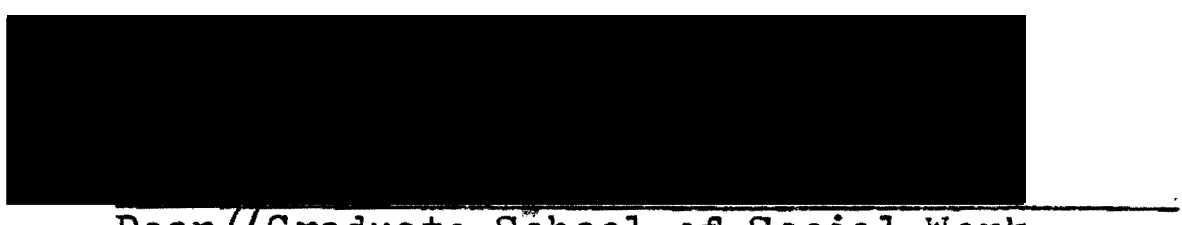

Dean//Graduate School of Social Work 
TABLE OF CONTENTS

Page

ACKNOMLEDGMENTS . . . . . . . . . . . . i

IIST OF TABLES. . . . . . . . . . .... ii

CHAPTER, , ,

I. INTRODUCTION. . . . . . . .... I

II. REVIFU OF IITERATURE. . . . . . . . . 5

Part 1. The Zung Self-Rating 0.6

Part 2. Depression ......... . . 12

Part 3. Symptomatology and Dynamics

of Adolescent Depression . . . . 17

III. METHODOLOGY . . . . . . . . . 30

The Sample... . . . 30

The Measurement Scale. . . . . . 32

Score Interpretation . . . . . . 33

Time Interval. . . . . . . . 33

Control Group. . . . . . . . . 34

The Data.......... . . 35

IV. PRESENTATION AND EVALUATION OF DATA . . . 38

General Information. . . . . . 38

Mean Scores for Non-Institutionalized

And Institutionalized Youths ...... 38

Mean Scores by Institution...... 39 

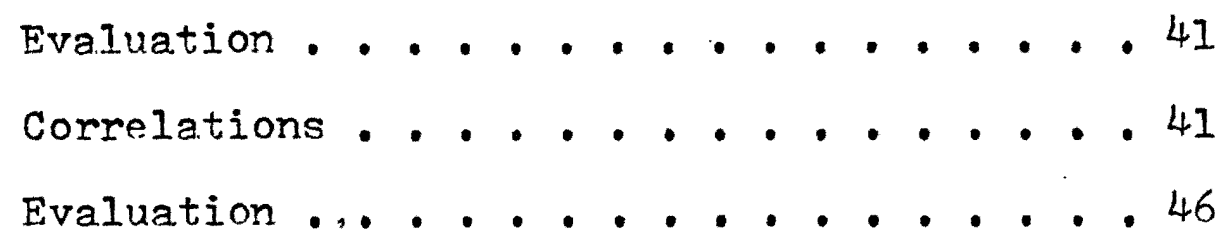

V. SUMMARY, CONCIUSIONS AND RECOMMENDATIONS 48

Implications for Further Study . . . . . 53

BIRIIOGRAPHY . . . . . . . . . . . . . . . 59 
ACKNOWLEDGMENTS

The research group wishes to express their appreciation to the staffs of the following residential treatment centers: Villa St. Rose, Parrot Creek Boys' Ranch, Youth Adventures and Family Service Center of Sioux City, Iowa. Our thanks is extended to Dr. Russ Sardo and Jay Lenhard. The kind cooperation and assistance of all of these people was helpful in preparing this practicum.

We are particularly grateful to Mr. Lewis Curtis and Dr. Quentin Clarkson. Mr. Curtis spent considerable time with us and has given us constant support and guidance. Dr. Clarkson's advice and encouragement was beneficial in making this project a. possibility. 


\section{IIST OF TABLES}

Table

Page

I Dverall SDS "ean Index Scores and Range of Scores for Control Group of Non-Institutionalized Youths and Mean Ratings and Ranges of Institutionalized Youths During Five months of

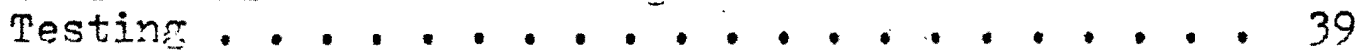

II SDS Mean Index Scores Attained By Sample Youths At Indicated Residential Treatment Programs During

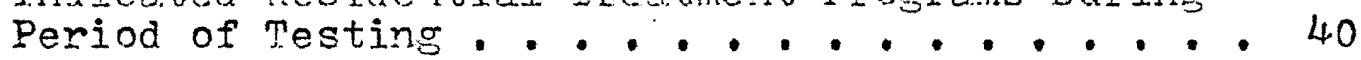

III Display of Change in the Correlation $\left(R^{2}\right)$ of Variate(s) To Post-Test Scores... . . . . . 44

IV Display of Significance/Non-Significance of Variate $(\mathrm{s})$. . . . . . . . . . . . 4 44

$V$ Comparison of Numbers of Institutionalized Adolescents with Natural/Non-Natural Parents. . . . . 45

VI Comparison of Numbers of Institutionalized Adolescents With One or Both Parents. . . . . . . 46 


\section{Chapter I}

\section{INTRODUCTION}

Increasingly larger numbers of people today are experiencing fatigue, boredom, restkessness, somatic problems, insomnia, disorganized thinking, and feelings of unworthiness and inferiority. Freud, (1) as well as severai theorists since his time, has described these complaints as symptoms of depression, and indeed, the person suffering from such symptoms most often will say he feels "depressed". But there are other symptoms of depression which are quite different from the ones described above, and which occur in depressed adolescents. J.M. Toolan (2) has pointed out that depression in adolescense is commonly demonstrated through an affect quite the opposite of that of an adult depressive; the youth may be seeking constant stimulation through loud music, alcohol, drugs, acting-out behavoir, and sexual promiscuity. This is in reaction to his feelings of boredom and restlessness. Youth displaying these symptoms are often labeled "delinquent". rather than depressed.

Concerned that depression might be a common malady among youth who are placed in treatment centers for delinquents, we

(1) Sigmund Freud "Mourning and Melancholia" in Standard Edition of the Comolete Psychological Works of Sigmund Freud, James Strachey (Ed.), London: Hogarth Press, 195?, Vol. 14. pp 243-258.

(2) J. M. Toolan, "Depression in Children and Adolescents" American Journal of Orthonsychiatry, Vol. 32, pp 404-415. 
undertook an exploratory study to determine the validity of this premise. The authors of this study have all worked with youth who, for various reasons, have been placed in residential treatment centers. The authors have observed that symptoms of depression seem to be more prevalent in these youth than in non-institutionalized adolescents, and that these symptoms are often perceived as individual pathology rather than emotional responses common to institutionalized youth. We thus began questioning if these were common emotional responses, and if they were common in males and females in a number of treatment centers. We were interested in knowing if the youth do in fact become more depressed after being admitted to a treatment center, and if they do, at what point in their stay at the center this occurs.

We feel the answers to these questions are important for several reasons. First, the authors are interested, for the purpose of their own professional practice, in understanding more about adolescent depression as it relates to institutionalization.

Secondly, comparatively little research has been done in this area. If our research indicated that depression is a common factor in adolescent institutions, this may stimulate more study of the problem.

Thirdly, if our study shows that a significantly high level of depression is common in youth during part or all of their stay in an institution, this may indicate different treat- 
ment approaches than may be presently used. For example, if we find that during a certain time-frame in the process of institutionalization most youth become significantly depressed, this depression may then be anticipated by staff and dealt with as an expected emotional response to institutionalization rather than as a pathology. Also, if we find that a significant number of institutionalized youth are significantly more depressed than the mean score for non-institutionalized youth, this may indicate that the delinquent or acting-out behavior for which they have been placed in the treatment center is actually symptomatic of depression. Again, this may indicate different treatment approaches.

In this exploratory study there may be a variety of findings :

(1) We expect to find that youth become more depressed after admittance to a treatment center than they were prior to admittance.

(2) Increased depression may occur within a predictable time frame during institutionalization.

(3) Depression may be associated with certain kinds of institutionalized youth. (This study includes demographic data on the youth's sex, age, race, and family background.)

(4) Depression may be associated with youth institutionalized in some treatment centers but not with youth in other treatment centers. 
Whatever the findings are, they will indicate a direction to follow in further study of depression in adolescent institutions. 
CHAPTER II

REVIEW OF LITERATURE

The review of literature is divided into three main sections. The first is litterature concerning the self-rating depression scale used in the study. We feel it is important to supply the information as to how the test was developed, and writings on the validity of the SDS.

The second section contains the literature we have put together on depression. We have included what we feel are the most comprehensive and significant theories on the symptomatology and dynamics of depression. We realize that there are numerous other authors who address themselves to depression and were not used in our review.

The third section on adolescent depression contains a.1 of the significant sources that we could locate conceming the symptomatology and dynamics of adolescent depression.

Our experience was that we found a great deal of literature dealing with "adult depression" and a minimum of literature pertaining to "adolescent depression". 


\section{PART 1}

THE ZUNG SELF-RATING DEPRESSION SCALE

The initial section of the review of literature will pertain to the literature that we found on the Zung Self-Rating Depression Scale. The material will be divided into two parts. The first dealing with the makeup of the test itseif; the second with the validity of the SDS.

The self-rating depression scale was originally devised as an attempt to quantitate the symptoms of depression, using the diagnostic criteria of the presence of a pervasive depressed effect, and its physiological and phychological concommitants as test items. (3)

The fact that there is a need for assessing depression, whether as an affect, a symptom, or a disorder is obvious by the numerous scales and inventories available and in use today. (4)

Dr. William K, Zung, (5) felt that the need to assess depression simply and specifically as a psychiatric disorder had not been met by most scales available. $Z$ ung was primarily

(3) Vulliam Ke Zung "Self-Rating Degression scale in an Vol. 13, (Dec. 1965), P. 508 .

(4) William K. Zung, "Evaluating Treatment Methods for Depressive Disorders", American Joumal of Fsychiatry, Vol. 124. (1968), P. 43.

(5) J. Gianturco, W. Zung, "Personality Dimension and the Self-Rating Depression Scale," Journal of Clinical Psychology, Vol. 12, (1971), P. 247. 
interested in having a scale for assessing depression in patients whose primary diagnosis was that of depressive disorder, which would fulfill the following requirements: It should be inclusive with respect to symptoms of the illness, it should be short and simple, it should be quantitative rather than qualitative, and it should be self-administered and indicate the patient's oum response at the time the scale is taken.

In devising the self-rating depression scale, the major clinical diagnostic criteria used were those most commonly found as characteristics of depression, i.e., dismalness, hopelessness, concern over material loss, anxiety, guilt, etc. (6)

Once the diagnostic criteria were established the next step was to devise a scale using these symptoms. To accomplish this, illustrative verbatim records were made from patient interview material. Examples selected were based on those statements which were mast representative for the particular symptom.

The scale was devised so that of the twenty items used, ten were worded symptomatically positive, and ten sympotomatically negative. In using the scale, the subjects are asked to rate each of the twenty items as to how it applied to each

(6) William Zung, "A Self Rating Depression Scale", Archives of General Psychiatry, Vol. 12, (1965) P. 66. 
of them at the time of the testing in the following four quantitative terms: a little of the time, some of the time, a good part of the time, most of the time.

The SDS is constructed so that the less depressed subject and his complaint will have a low score on the scale, and the more depressed patient and his complaint will have a higher score. In scoring the SDS, a value of $1,2,3$, and 4 is assigned to a response depending upon whether the item is worded positively or negatively.

An index for the SDS was derived by dividing the sum of the values (raw scores) obtained on the twenty items by the maximal possible score of 80 , and expressed as a decimal. (7) In developing the SDS Dr. Zung felt that it would include all of the important diagnostic criteria of depression and that it would be a useful and easy to use tool. From results obtained in the use of the SDS it does appear that the SDS is useful in quantitating depression as a disorder. (8)

In comparing the SDS with the MMPI, a significant correlation was found between the depression scale of the MMPI and the SDS. (9)

(7) 'Tbid,: P. 68 .

(8) Joseph Marone, B. Iubin, "Relationship Between the Depression Adjective Checklists and Zung Self-Rating Depression Scale", Psychological Reports, Vol. 22, (1968) P. 334 .

(9) Op. Citt.., William 2ung, "Self-Rating Depression Scale in an Outpatient CIinic", P. 510. 
Another study was done comparing the mean index of two separate tests using the SDS. One test was conducted with a group of psychiatric outpatients who were diagnosed as having depressive reactions. The mean index in this testing was 64. The other study, with a group of hospitalized inpatients produced a mean index of 74 . In both studies, there were patients who were diagnosed as having anxiety reactions, personality disorders, psychophysiological reactions, and transient situational adjustment reaction. In each of these studies, the mean SDS index for all the patients was 53. Thus, with two entirely different populations of subjects, all with similar psychiatric diagnosis, the rating of their depressive symptomatology by the SDS was fairly stable. (10)

An additional study was done in which a statistically significant correlation was found between the SDS, and the Byrne and Ullman sensitization dimension scales. The findings indicate that subjeats with depression do not repress or deny their illness and are proportionately sensitive to their symptoms when given varjations of a depression test. (11).

During the course of an evaluation of an experimental anti-depressant, observations led to the hypothesis that one

(10) B. F. Carroll, J. Fielding, T. Blashia, "Depression Rating Scales, Critical Review", Archives of General Psvchia.try, Vol. 28, (1973) P. 363.

(II) "Op. Cit.." J. Gianturco, P. 249. 
could differentiate, on a clinical basis, patients in whom one could expect an unreliable correlation between scores obtained on the 2 ung scale and the Hamilton physician rating scale. (12)

The Hamilton Physidian Rating Scale, is a scale composed of depressive characteristics and designed for use in diagnosing depressive conditions in hospital patients.

It was found that the $Z$ ung and Hamiltion depression scales correlate significantly. It was also discovered that those patients who correlate the least predictably in terms of the Zung and Hamilton scales tend to fall into groups of marked sensitizers, or marked repressors, both of whom are easily identifiable clinically, and may be further objectively determined by the use of appropriate MMPI sub-scales.

In conclusion, this study stated, "All in a.ll, the Zung Scale has the advantage of ease of administration, and there seems to be no significant difference between the accuracy of the zung and the Hamilton."

Using the SDS, Dr. 2 ung found that self-ratings of depressed patients were comparable between countries, and differed significantly from the scores of normal subjects and non-depressed patients. (13)

(12) C. Chien, R. Kaplan, "Clinical Trial of Imadazolina, as an Anti-Depressant", Current Therapy, Vol. 13. (1971) P. 577 .

(13) Richard Mikese11, L. Calhoun "Response Set on the Zung SDS", Perceptual and Motor Skills, Vol. 30, (1970) P. 22. 
In another study, a high correlation was found between the $\mathrm{zung}$ Self-Rating scale and the physicians global ratings of depressed patients, as well as petween scores on the SDS and other specific depression rating scales. The test subjects were divided into two groups, those with diagnosis of depressive disorders, and those with other primary diagnosis. They then were divided into those who were treated and those who were not. Statistical analysis using the test were performed and the mean SDS indices were significantly different for those who were treated as opposed to those who were not.

The correlation of the SDS with the physicians global ratings and with other depression scales indicates its reliability in measuring depressive symptomatology with some consistency. The ability of the SDS to predict which patients will be treated for depression, as compared to the global rating is further indication of the validity of the SDS. (14)

(14) G. Brown, W. Zung, "Depression Scales; Self-Rating or Physician Rating Validation of Certain Clinically observable Phenomena", Journal of Clinical Pharmacology, Vol. 12. (1972) P. 364. 
PART 2

DEPRESSION

This section contains a summary of the literature that we reviewed pertaining to depression. The first part will focus on the symptomatology and the second will deal with the basic theories on the dynamics of depression.

Not too surprisingly, the first author we turn to is Preud, (15) In 1917 he wrote a paper entitled "Mourning and Melancholia" where he provided the following clinical description of depression. "The distinguishing mental features of melancholia are a profoundly painful dejection, cessation of interest in the outside world, loss of the capacity to love, inhibition of all activity, and a lowering of self-regarding feelings to a degree that finds utterance in self-reproaches and self-revilings and culminates in a delusional expectation of punishment."

In reviewing extensively other theoritician's views on the symptomatology of depression we found the most comprehensive was formulated by Beck. (I6) Beck divides the symptoms into four main categories. (1) Emotional manifestations -dejected mood, negative self attitudes, reduced experience of satisfaction, decreased involvement with people and activities, crying spells, and loss of sense of humor. (2) Cogintive manifestations -- low self-esteem, negative expectation for the fu-

(15) Sigmund Freud, "Mouming and Melancholia". Standard Edition, Vol. XIV, (1957), P. 245.

(16) A. T. Beck, Depression: Clinical, Experimental and theoretical Aspects, (New York, 1967) P. 58 . 
ture, self punitive a.ttitudes, indecisiveness, and distorted body imagery. (3) Motivational manifestations -- loss of positive motivation to perform tasks, escapist and withdrawal wishes, suicidal preoccupations, and increased dependency. (4) Vegetative and physical manifestations -- loss of appetite, sleep disturbance, decreased sexual interest, and increased fatiguability.

In terms of the dynamics of depression. Freud says the real or fantasized loss of a love object is a. central etiologic element in the characteristic sadness of the depressed person. (17) Beck agrees with Freud on this point, but he sees fantasied deprivation as only one of three patterns of misinterpretation of the experience that participate in creating depression. His other two patterns are (I) unrealistic negative images of oneself, which lead to apathy, feelings of helplessness, increased dependency wishes, and suicidal tendencies associated with depression. (2) unrealistic negative expectations of the future, which underlie the depressed persons usual pessimism. (18)

Another significant addition to Freud's formulation of depression is contributed by Bibring, (19) who feels that fail-

(17) Op. Cit. Freud, P. 247.

(18) Op. Cit. Beck, P. 63.

(19) E. Bibring, "The Mechanism of Depression", Affective Disorders, (1953) P. 30. 
ure to realize one's aspirations, is an essential element in depressive disorders. "What has been described as the basic mechanism of depression, the ego's shocking awareness of its helplessness in regard to its aspirations, is assumed to represent the core of normal neurotic and probably psychotic depression."

Bibring was the first to look at depression in terms of ego psychology. He states "the ego is fixated at the oral defense mechanisms". Other theories view depression as a conflict between the id and the ego. Bibring sees it as within the ego itself. In doing this he contrasts anxiety and depression. Anxiety he sees as a reaction to danger. The ego prepares for fight or flight. In depression, the opposite occurs. The ego is paralyzed because it is incapable of meeting the danger.

Bemporad (20) takes a slightly different view of the psychodynamics of depression. His theory contains four crucial aspects. (1) Dependency on a dominant other -- the individual fails to derive satisfaction from independent achievement. (2) Fear of autonomous gratification -- accomplishments bring little pleasure in themselves, rather they are sought in an attempt to win love and acceptance from an external agency. (3) Bargain relationships -- denying self autonomous satisfac-

(20) Jules Bemporad, "New Views on the Psychodynamics of the Depressive Character", The World Bienniall of Psychiatry and Psychotherapy, (1971) P. 134 . 
faction in return for nurturance from the dominant other. Inability to alter the environment -- a sense of hopelessness and dispair.

According to Bemporad, the family background of the depressed person could be described as follows: (1) Skewed parental authority - children not receiving a blending of matemal and patemal values. (2) The family operates as a closed system. (3) There is an over value of achievement and worldly success. (4) Independency and rebelliousness of the child are very threatening to the mother.

A main theme found in Bemorads view is that the mothers of depressives, exploitively try to derive strength and gratification from the child rather than imparting a sense of well being and freedom.

Rado (2I) presents a modification of an earlier theory of his when he states that depression is an unconscious cry for love precipitated by an actual or imagined loss.

Whereas Freud: would see self-punishment as an accidental and incidental attack on the internalized mother, Rado sees it as real self-punishment for the rage felt toward the love object. Rado feels that the ambivalence seen in depressed patients is the conflict between coercive rage and submissive fear.

(21) Sandor Rado, The Meaning of Despair, Edited by Gaylin, (New York: Science House, 1968) P. 131. 
Fenichel (22) sees depression as a means of avoiding total dissipation of self-esteem. He feels the precipitating experience not as necessarily a loss of love object, but as a. loss of self-esteem, or a loss of the supplies which can enhance or secure self-esteen.

In 1927, Karl Abraham, (23) in his theory of depression made a definite distinction between normal mouming (grief) and melancholy (depression). He felt that the difference was the presence of anger, or "unconscious hostility". Abraham felt that the reaction to the loss of a love object results in melancholy if the reaction to the loss is charged with rage and hosbility.

He states that those who become depressed (precipitated by loss of love object) are those who have had an early "narcissistic injury" and have an oral pre-disposition. Those who become depressed are essentially dependent people with certain basic defects in their self-esteem and self-pride system.

(22) Fenichel, The Meaning of Despair, Edited by Gaylin, (New York, Science House, 1968) P. 154.

(23) Karl Abrahan, "Notes on the Psychoanalytic Investigation and Treatment of Manic-Depressive Insanity and Allied Conditions," Selected Papers on Psychoanalysis, (1953) P. 327 . 
PART 3

SYMPTONATOLOGY AND DYNAMICS

OF ADOLESCENT DEPRESSION

Irving Weiner (24) points out that among adolescents the clinical manifestations of depression may vary considerably from the typical patterns which we described in the previous section. He states that this is particularly true in the younger teenager. He goes on to say that the traditional symptom picture of depression, rarely appears before the age of seventeen. However, despite the infrequent emergency of traditional depressive symptomatology before late adolescence, clinical experience indicates that essentially depressive disorders are by no means rare in early adolescence.

Weiner states that the younger person, more than the older teenager, tends to manifest depression primarily through

- a number of non-traditional symptomatic expressions. He feels that it is helpful to consider separately for early and late adolescents the clinical manifestations by which depression can be recognized.

Gould (25) states that the early adolescent, as a consequence of his usual disinclination to express his feelings openly and his tendency to deny self-critical attitudes, is relatively unlikely to exhibit the gloom, hopelessness, and self-depreciation that commonly key-note adult depression. He goes on to say that the relative impulsivity of children

(24) Irving Weiner, Psychological Disturbance in Adolescence, (New York, Wiley, Interscience, 1970), P. 165.

(25) R. E. Gould, "Suicide Problems in Children in Adolescence and Children", American Joumal of Psychotherapy, (1965) P. 230 . 
and early adolescents typically leads them to express depressive states through behaviors that cloak the depression and disguise the diagnosis.

In 1967, Glaser and Toolan (26) elaborated what they feel are the major depressive equivalents observed in young people.

(1) Boredom and restlessness, i.e., the youngster who altemates between total disinterest and intensive preoccupation with activities; or the youth who cannot tolerate being alone.

(2) Fatigue and bodily preoccupation, i.e., the adolescent who altemately feels bouyantly energetic and overwhelmingly fatigued, particularly when his fatigue persists after adequate sleep.

(3) Concentration difficulty. This has specific signifigance as a depressive equivalent because of the frequency with which it is the chief or sole complaint that brings a youngster for help. The concentration difficulty is typically described in relation to declining school performance. The depressed early adolescent is seldom able to account for his concentration problem.

(4) Acting out. In many instances acting out behavior including temper tantrums, running away, and a variety of de-

(26) K. Glaser, R. Toolan, "Masked Depression in Adolescence and Children". American Journal of Psychotherady, (1967) P. 567 . 
fiant rebellious, anti-social and delinquent acts serve to defend an early adolescent against coming to grips with underlying concepts of himself as an unloved, inadequate and unworthy person. Not only does the acting-out prelude thinking as the common adage prescribes, "Try to keep busy and not think about it", but the actions themselves, to the extent that they are hazardous or exploitive, may be designed to inflate the youngster's self image as a tough, brave, and clever person.

Burks and Harrison (27) concur with the acting out as a mask of depression. They state that impulsive anti-social a.ggressive behavior functions as a means of avoiding feelings of depression, or a depressive state. The acting out serves to relieve the inner tension the adolescent may be experiencing. In a study they undertook, they encountered a number of devices utilized by young adolescents apparently aimed at avoiding recognition of a fundamental state of helplessness or powerlessness of the ego, which is associated with a depressed afffect.

The youths in their study engaged in acting-out and defiant behavior and ignored ordinary conventions and dengers. They were insistent in denying fears of inadequacies. However, it was readily apparent that this was a merely shallow display of bravado.

(27) H. Burks, S. Harrison, "Aggressive Eehavior as a Means of Avoiding Depression", American Joumal of Orthonsychiatry, (1962) P. 420. 
Keeler, Shore and Speed (28) state that it is not infrequent for delinquent acts to appear directly after the loss of a. loved person and thus to represent a manifestation of the mourning process. They cited a number of cases in which death of a parent or relative was closely followed by conspicuously anti-social behavior in previously conforming youngsters who gave no evidence of psychological disturbance.

Jacob Chwast (29) undertook a study to discover depressive reactions as manifested by adolescents. His findings state that there is a large depressive component in the personality structure of delinquent (acting out) adolescents. Delinquent adolescents tend to be more, rather than les depressed. He sees depression as the result of serious emotiona.I and social deprivation and anti-social behavior a means of discharging a depressive underlay through action.

An interesting aspect of his study is that he states that delinquent girls are more depressed than boys. He hypothesizes that girls conform more to cultural restraints in

(28) W. Keeler, S. Shore, I. Speed, "Childrens Reactions to the Death of a Parent", Depression, Edited by P. Hoch, (New York, 1954) P. 110.

(29) Jacob Chwast, "Depressive Reactions as Manifested Among Adolescent Delinquents", American Joumal of Psycho-: therapy, (1967) P. 575. 
their behavior and consequently have a larger amount of inner stress and conflict.

John Meeks (30) states his position that adolescent sexual acting out is an attempt to hide depression. He states that psuedo homosexuality among male adolescents, may be a reaction to a setback with a female and creates the need for dependency on a strong male figure.

(5) Flight to or from people. Glaser (31) states that a final clue to underlying depression in adolescents who do not otherwise display traditional depressive symptoms is an exaggerated approach to, or withdrawal from people. He agrees with Meeks when he states that in some instances, the urgent necessity to ward off underlying feelings of being unloved and unwanted pushes the adolescent toward promiscuis sexual behavior, in which close physical contact with another person who expresses interest and affection, for whatever reason, provides the major gratification.

The depressed adolescent's feelings of abandonment and unworthiness often leads him to tum away from, rather than toward people. They often shun people primarily to avoid being reminded that he feels abandoned and rejected by them.

(30) John Meeks, The Fragile Alliance, (Baltimore, 1971), P. 135.

(31) "Op. Cit." Glaser and Toolan, P. 570. 
Glaser also states that it is not unusual for a depressed youngster to turn $h$ is attention specifically away from people and toward animals. The adolescent who selects animals as his love objects and devotes major attention to their care and feeding may be revealing underlying depressive reactions to feeling rejected by the important people in his life.

Moving into late adalescence, weiner (32) states that the clinical manifestations of depressive disorder increasingIy resemble the symptom pattems that are characteristic of adult depression.

In 1961 Binger (33) noted that college girls were particularly prone to traditional depressive reactions marked by apathy and fatigue, considerably lowered self-esteem and. an inability to get work done.

Walters ( 34 ) points out that a particularly common channel for underlying feelings of hopelessness, despair, and inadequacy in late adolescence of both sexes is a pervasive apathy that simultaneously expresses and defends against what is essentially a depressive disorder. He elaborates that apa-

(32) "Op. Cit.." Weiner, P. 172.

(33) C. Binger, "Emotional Disturbances Among College Women". Emotional Problems of the Student, Edited by G. Blain, (New York, 1961), P. 173.

(34) P. Walters, "Student Apa.thy", Emotianal Problems of the Student, Edited by G. BIain, (New York, 1961), P. 181. 
thetic young people are frequently mired in self-depreciation, expectations of failure in their academic efforts, humiliation in their personal engagements, and defeat in their quest for an independent and mature identity.

Their depressive state can usually be recognized from their physical lethargy, decreased interest in people and events, and emptiness of feeling, all of which they fully sense.

Shainberg (35) pointed out that this pattern of personality restriction as a manifestation of depression is not 1 imited to the late adolescent who is in college. He observed a similar pattern in a group of late adolescent boys, most of whom were school dropouts. He found that these individuals were reluctant to think about anything but immediately current circumstances, were persistently hopeless about their situations, and were willing to settle for anything that came their way without having to exert themselves.

Regarding the dynamics of adolescent depression, Weiner feels that the underlying theme in adolescent as well as in adult depression is the experience of loss; loss of personal relationship through death, separation, or a broken friendship; loss of self-esteem after failure to attain a desired and an-

(35) D. Shainberg, "Personality Restrictions in Adolescent", Psychiatric Quarterly, (1966), P. 394. 
ticipated goal or the commission of a regretted act; loss of bodily integrity in connection with illness, incapacitation, or disfigurement. (36)

In adolescents as in adults these losses may be actual events that precipitate a rexctive, self-limited depression -such as rejection by a boyfriend, failure to make the football team, or an eruption of' acne or they may constitute unconscious or unrealistic fantasies that Iead to the more persistent endogenous depressions.

Samuel spector (37). states his position that adolescent depression relates to specific developmental tasks of the adolescent. "Of all the states of man's development, adolescence is the most difficult. Some of its aspects are: insecurity, identity, confusion, struggle for self-esteem, alienation, and desire for peer acceptance". Spector feels that these feelings sensitize teenagers to the experience of object 10ss. It is during the adolescent years that young people are encouraged to loosen their ties to their parents, who have previously been their primary love objects, authority figures, and sources of dependent gratification. The adolescent is increasingly expected to forego dependent gratification, to pur-

(36) "0p. Cit." Weiner, P. 213.

(37) Samuel Spector, "The Problem Adolescent", Adolescence, Vol. II, (1967), P. 8 . 
sue peer-group activities outside his home, and to rely on teachers and other extrafamilial models for guidance.

Spector feels that the adolescent typically experiences mixed feelings about relinquishing his childhood, and that these feelings may lead to depressive states in the adolescent.

This aspect of adolescent development has been most clearly elaborated in the psychoanalytic literature. Freud, (38) in one of his early works described the detachment from parental authority as "one of the most significant, but also one of the most painful, psychic achievements of the pubertal period."

Root (39) asserts that all adolescents must sooner or later renounce and suffer the "loss" of their childhood aims and objects. Iorand (40) explains the role of such loss in the following way:

(38) S. Freud, "Adolescence", Psychoanalytic Study of the Child, (i958), P. 260.

(39) N. Root, "A Neurosis is Adolescence", Psychoanalytic Study of the Child, (1958), P. 321.

(40) S. Lorand, "Adolescent Depression", International Journal of Psychoanalysis, (I967), P. 57. 
"The painful psychic achievement of the adolescent -- his detachment from parental authority - is so painful precisely because he experiences it not as a liberation but as an abandonment by those objects on whom he relies for guidance and support. Hence the reluctance sets in, accompanied by feelings of aloneness, emptiness, and helplessness, and a resentment toward the idea of abardoning the past."

Anna. Freud and Jacobson (41) suggest that such Iosses frequently induce apparent states of grief ar mourning in adolescents that may persist until they have successfully disengaged themselves from their parents and embarked on $a$ quest for new objects.

Laufer (42) ascribes the impact of actual object loss in adolescence in part to its being imposed on a normal mourning process. He states, "While not itself pathogenic, object loss can become the nucleus around which earlier conflicts and the latent pathogenic elements are organized. The detachment from the oedipal object is a normal developmental task in adolescence, which may be greatly complicated by the actual loss of the object."

Weiner (43) states that it would be misleading to regard depressive states as normal or normative adolescent phenomena.

(41) A. Freud, E. Jacobson, "Adolescent Moods and the Remodeling of Psychic Structure in Adolescence", Psychoanalytic Study of the Child, (1958), P. 362 .

(42) M. Laufer, "Object Loss and Mourning During Adolescence", Psychoanalytic Study of the Child, $(1966)$, P. 270.

(43) "0.p, cit," Heiner, P. 181. 
On the other hand, a dymamic understanding of personality development indicates that adolescence, like other transitional periods of life that involve surrender of previous gratifications, does enhance the individual's susceptibility to depressive reaction. It is generally the case that, the less able a youngster is to embrace adolescent development and to give up his infantile attachments, the more prone he will be to experience loss and subsequent depression in the face of parental and environmental expectations as he grows up. Beyond. this principle the sufficient conditions for depressive reaction lie for the most part in the nature of definable losses the adolescent happens to experience and the extent of $\mathrm{h}$ is predisposition to depressive reactivity in the face of stress. A number of studies suggest that the propensity for depression in the face of loss is directly related to childhood experiences of parental deprivation that sensitize the individual to such losses. Brown, (44) for example, found that 41 per cent of a sample of depressed adults had experienced loss in the general adult population from which his depressed sample was drawn. "Masterson, Tucker, and Berk (45) similarly noted

(44) F. Brown, "Depression and Childhood Bereavement", Journal of Mental Science, (1961), P. 76.

(45) J. Masterson, K. Tucker, G. Berk, "Psychopathology in Adolescence", American Journal of Psychiatry, (1963) P. 357 . 
a. prominent incidence of parental death, separation, or divorce in depressed 16 to 18 year old youngsters they studied. Jacobs and Teicher (46) found an equal incidence of parental loss in childhood among suicidal and non-suicidal teenagers matched for age, sex, race, and family income. On the other hand, 80 per cent of their suicide attempters and only 45 per cent of their control subjects demonstrated depressive affect or withdrawal. In assessing their data Jacobs and Teicher emphasize that it is not the actual loss or presence of a parent that is crucial in the etiology of depressive disorder in adolescents, but rather the entire process by which love objects participate in the youngster's development. Elson (47) discusses the similariy variable impact of separation on the late adolescent who goes off to college. The nature of the depressive features in the students he sampled was related to the stability and orientation of the family subsequent of the youngster's leaving for school. Where parents denoted the college students departure as the time for a major shift in their orientation, such as increased attention to younger children or previously dormant commitments, decision to divorce preparation for an extended trip, or move to a dif-

(46) J. Jacobs, J. Teicher, "Broken Homes and Social Isolation in Attempted Suicide of Adolescents", International Joumal of Social Psychiatry, (1967), P. i 49.

(47) M. Elson, "The Reaction Impact of Adolescent and Family upon Each Other in Separation," 'Journal of American Academy of Child Psychiatry; (1964), P.708. 
ferent house, the youngster's reaction to the separation was more likely to have overtones of anger and guilt than if he was voluntarily relinquishing parental ties.

In summary, it appears that the period of adolescence itself is such a difficult task that its depressive symptomatology may result. It also appears that the task of adolescence, coupled with the real or fantasied loss of a. love object may bring about a state of depression in the adolescent. 


\section{CHAPTER III}

\section{METHODOLOGY}

In our study the major question being explored is whether or not most adolescents became significantly depressed when institutionalized. The size of our sample was important, as too small a sample would not yield results that can be shown valid, statistically.. Regarding sample size, it was important to initially have at least 40 adolescent subjects from more than one treatment center, for the following reasons:

A. To allow for the loss of some subjects who run away from the treatment center.

B. To obtain a sample of youth from a number of residential treatment centers and varied settings, i.e., urban, rural.

C. To obtain a larger diversity of youth, as some treatment centers have populations of mostly one kind of youth based on sex, age, race, income level, type of offense, etc.

The Sample:

Youth chosen for testing were all those between the ages of 14 to 20 who were admitted to one of the four treatment centers between the dates of August 1, 1973 and November 2, 1973. If a youth had previously resided for over three months in the same treatment center to which he was being admitted, he was not used in our sample. Only one new admittance was rejected on this basis. 
We chose four residential treatment centers in which to do the testing. These centers were: Villa St. Rose, Parrot Creek Ranch, and Youth Adventures, all in or near Portland, Oregon; and Family Services, in Sioux City, Iowa. These particular centers were chosen because we had at some time had contacts with them, and because they were not only interested but very cooperative.

The aforementioned treatment centers basically serve the same population, which is youth who, because of acting-out behavior, have been labeled status offenders or delinquents and usually have been adjudicated through a juvenile court. However, the programs differ in some respects.

Youth Adventures is situated in a country environment, and its program features outdoor type of activities such as hiking, camping and backpacking. The population is relativeIy small, about 15 boys. There is also a girls' program which is physically separate from the boys and was not used for this study. The treatment program includes counseling and group works, and youth attend public school outside of Youth Adventures.

Parrot Creek Ranch is also in a country setting and has a program similar to the one described above. The population is all male and consists of about 18 boys. There are outdoor activities in the program and counseling and group sessions. Classes are held on the Ranch, some youths attend school in the community. 
Villa St. Rose is a larger center and is located within the city of Portland. It has an all-female population of 4550. It is housed within one building, including a public school which girls attend daily. However, girls are allowed to leave the premises at specified times. Both counseling and group work are part of the treatment.

Family Services is within the city of Sioux City, Iowa and has a population of about 32 youths, all male. The youths attend school on the premises. Both counseling and group work are offered.

The Measurement Scale:

In choosing an appropriate measurement of depression we looked for one which was not too subjective, such as behavioral observations, and which could be used easily and quickly, and would have validity when used Iongetudinally. The Zung SelfRating Depression Scale (SDS) seem to best fit our needs. The test was designed by William W. K. Zung M.D. and was first published in 1965 in a series of reports on patients with depression and other emotional disorders. It is a scale of 20 questions which can be self-administered by the youths and which takes only about 10 minutes to complete. Statistical studies indicate that this measurement correlates reliably with other more time-consuming depression rating scales.

The scale itself is comprised of a list of 20 items, each relating to a specific characteristic of depression. Next to the items are the four frequency columns. The indi- 
vidual is given the list of items and is asked to put a checkmark in the box most applicable to him at the time of the test. A raw score is then tabulated and is converted to an index score based on 100. The scale is constructed so that a low index indicates an insignificant level of depression and $a$ high index indicates depression of clinical significance. Score Interpretation:

For the purpose of interpretation of SDS Index ratings, Zung has offered the following table:

Diagnosis of Validating Groups

Normal Controls

Depressed (hospitalized)

Depressed (out-patient)

Anxiety Reactions

Personality Disorders

Transient Situational

Adjustment Reactions

\section{Mean \\ SDS Index \\ Range}

33

74

64

53

53

53
$25-43$

$63-90$

$50-78$

$40-68$

$42-68$

$38-68$

The above categories were obtained in generally adult patients who had been diagnostically evaluated prior to SDS administration by clinitians other than $\mathrm{Zung}$ and by standard depression measure scales. Zung reported "a high correlation between SDS scores and the separate assessments." (48)

Time Interval:

Since we were interested in assessing a relationship between depression and placement in a treatment center, we wanted to know how depressed $a$ youth was at admission and compare this to later scores obtained some time after he had been ad-

(48) William W. K. Zung, "The Measurement of Depression" Lakeside Laboratories, Inc., Milwaukee, 1967, p. 5. 
mitted. For obvious reasons we found it too difficult to test him prior to admission, but our first test was given within 24 hours of admission to the center. We then tested him again two weeks after the first test, again at six weeks after admission, and finally one week prior to release, or five months after admission, whichever came first. The purpose for giving tests at these time intervals was to try and determine whether, if a youth does become depressed, it is most often nearer his time for release, and if the depression decreases at some point in his treatment.

The tests were presented for self-administration by $a$ staff person in each treatment center, and to avoid scewing data, the tests were scored by the practicum team and scores were not shared with other staff or youth.

For the purpose of exploring correlations between depression and personal and environmental differences of the youths, we collected the following demographic datas sex, age, living with natural or adoptive or foster parents and lixing with a single or bath parents. Some other data which was assumed might correlate with depression was unavailable on many case records and therefore was not studied. Control Group:

Additionally, ten non-institutionalized youths were tested at John Adams High School in Portland, Oregon. These youths were chosen at random from high school classes, and were tested once in the month of October of 1973. Although 
this did not constitute a meaningful: control group, it did help in establishing a mean score for adolescents on the SDS. This was important as the degree of depression categories on the SDS had been established using adult subjects. The Data:

Mikesell and Calhoun in their examination of the scale tested a group of thirty high school students. The students received a mean index rating of 48.1 which led the researchers to conclude that SDS Index scores "seem to be inflated". They suggested that "separate norms should be developed". (49)

As indicated, a control group of ten John Adans High School students was given the Zung to establish norms for interpretation. This group achieved a mean score of 51.5. According to the $\mathrm{Zung}$ interpretive classifications, these adolescents had a mean which placed them in the following categories: Depressed (out-patient), Anxiety Reactions, Personality Disorders, Transient Situational Adjustment Reactions. Mikesell and Calhoun's group would fall into the latter three categories.

In consideration of the above, for the purposes of our study, we assumed that a deviation of ten points in either direction from the John Adams control group mean was a more meaningful measure of significant categorical change than the

(49) Mikesell, R. H. and Calhoun, L. G. "Faking on the Zung SDS", Psychological Reports, Vol. $25 \mathrm{pp}$. 173-174. 
Zung range mean. For example, given that a mean index of 51.5 was established as the base average for Normal Controls, 10 points above this score, 61.5 , would be in the categories: Anxiety Reactions, Personality Disorders, Transient Situational Adjustment Reactions.

For assessment purposes, a multiple regression, multiple estimating equation was atilized tetermine how much of the dependent variable $(Y)$ of the Self-Rating Depression Scale scores of institutionalized adolescents could be correlated with combinations of independent variables $\left(x_{1}, x_{2}\right.$, etc.) at specified time intervals. The significance of any relationship was evaluated on an $F$ test.

The first test given, the one administered within 24 hours of admission to the treatment center, will be used to establish a baseline, and will be referred to as the "pretest".

In organizing the data, there will be four major areas we will want to consider:

A. Is the mean score for institutionalized youths significantly higher than for non-institutionalized youths? In other words, are instituionalized youths significantly more depressed than non-institutionalized youths?

B. Does the mean score of institutionalized youths increase with time in the institution, or does it decrease, or is there insignificant categorical change?

C. If there is a change in the depression level, does it correlate significantly with any of the demographic data previously described? If 
a change occurs, does it occur in all the treatment centers in which we did testing, or does this vary?

D. Observations will be made of the pre-test scores of the youths who ran away from the treatment centers. These scores may indicate significantily higher or lower scores than those of youths who did not run away.

Charts will be used to illustrate depression rates longetudinally and their correlation to the demographic data. In our final chapter we will speculate on some of the possible reasons for our findings. 
CHAPTER IV

PRESENTATION AND EVAIUATION OF DATA

\section{General Information:}

The samples from which our data were obtained initially consisted of 31 youths. Two factors reduced the size of this sample to 27. Two youths: ran away, That some of these adolescents would run during the test period was assumed and observations were made of their test scores prior to running. This will be discussed in the presentation. In addition, just before the final testing, one institution withdrew from the study due to what they described as "staff turnover". In this manner two more youths were eliminated from the final testing.

Mean Scores for Non-Institutionalized And Institutionalized Youths:

The mean SDS Index rating for non-institutionalized youths was 51.5. Institutionalized adolescents had a mean of 54.6 at the pre-test, 51.8 at two weeks, 53.6 at six weeks and five months. (Table I) 
TABLE I

OVERAII SDS MEAN INDEX.SCORES AND RANGE OF SCORES FOR CONTROL GROUP OF NON-INSTITUTIONALIZED YOUTHS AND MEAN RATINGS AND RANGES OF INSTITUTIONALIZED YOUTHS DURING FIVE MONTHS OF TESTING

\begin{tabular}{lccccc}
\hline & $\begin{array}{c}\text { Non-Institutionalized } \\
\text { Control }\end{array}$ & \multicolumn{4}{c}{ Institutionalized } \\
\hline MEAN & 51.5 & 54.6 & 51.8 & 53.6 & 53.6 \\
\hline RANGE & $41-61$ & $42-79$ & $35-73$ & $35-73$ & $34-68$ \\
\hline
\end{tabular}

The mean scores registered for institutionalized youths were not significantly different from the mean obtained in non-institutionalized adolescents.

Scores received on the $\mathrm{Zung}$ ranged from a high of 61 to a low of $4 \mathrm{I}$ in the John Adams group. Institutionalized youths' scores ranged from a high of 79 on the pre-test to a low of 34 at the fifth month.

SDS Index ratings were both significantly higher and lower, more extreme, for the sample of institutionalized youths, (Table I) than for the sample of non-institutionalized youths.

\section{Mean Scores by Institution}

Comparisons were made between the mean SDS Index scores achieved by the youth sample in each of the participant residential treatment programs during the period of testing. Family Service, Inc. had a mean score of 55 at the pre-test, 54.2 at two weeks, 58.2 at six weeks, and 55.2 at five months. Villa. 
St. Rose achieved a mean rating of 54.2 on the pre-test, 54.9 at two weeks, 55.9 at six weeks and 56 at five months. Parrot Creek Boys Ranch had a pre-test mean of 60.2 , a two week rating of 45 and a six week and five month mean score of 42 . Youth Adventures, Inc. residents sampled attained a mean index rating of 42.5 in the pre-test, 40 at two weeks and 41 at six weeks. This center withdrew from the study prior to the final testing. (Table II)

\section{TABLE II}

SDS MEAN INDEX SCORES ATTAINED BY SAMPLE YOUTHS

AT INDICATED RESIDENTIAI TREATMENT PROGRAMS

$$
\text { DURING PERIOD OF TESTING }
$$

\begin{tabular}{lcccc}
\hline Institution & Pre-Test & 2 Weeks & 6 Weeks & 5 Months \\
\hline $\begin{array}{l}\text { Family } \\
\text { Service }\end{array}$ & $55: 0$ & 54.2 & 58.2 & 55.2 \\
\hline $\begin{array}{l}\text { Villa } \\
\text { St. Rose }\end{array}$ & 54.2 & 54.9 & 55.9 & 56.0 \\
$\begin{array}{l}\text { Parrot Creek } \\
\text { Boys Ranch }\end{array}$ & 60.2 & 45.0 & 42.0 & 42.0 \\
\hline $\begin{array}{l}\text { Youth } \\
\text { Advantures }\end{array}$ & 42.5 & 40.0 & 41.0 & $-\ldots-$ \\
\hline
\end{tabular}

In three of the institutions no significant change in mean SDS Index ratings occured during the period of testing. In one institution, Parrot Creek Boys' Ranch, a drop of 5.2 points in the $z$ ung rating eventuated between the initial test and the second week of testing. No significant change happened at the third (sixth week) and final (fifth month) testing. 
Evaluation:

A comparison of the mean Self-Rating Depression Scores of institutionalized and non-institutionalized youths reveals that there is no meaningful, significant difference between them and that neither group is very depressed.

Information conceming a change in mean scores of institutionalized adolescents with time shows that, over-all, there is no substantive alteration in the low level of depression of these youths throughout the period of residency, 0-5 months. Considered individually, one of the four residential treatment programs exercised a decrease in the mean SDS Index score. However, this was not meaningful in terms of a categorical alteration in the level of depression. This change was apparent at two weeks and remained essentially stable.

\section{Correlations:}

To restate from the previous chapter, for assessment purposes, a multiple regression, multiple estimating equation was utilized to determine how much of the dependent variable ( $Y$ ) of the Self-Rating Depression Scale scores of institutionalized adolescents could be correlated with combinations of independent variables $\left(X_{1}, X_{2}\right.$, etc.) at specified time intervals. The significance of any relationships was then evaluated by an $F$ test. The multiple regression equation is represented as follows:

$$
Y=B_{0} X_{0}+B_{0} X_{2}+B_{2} X_{2}+B_{3} X_{3} \text { to } B_{7} X_{7}-E
$$


Variates anplied to the sample of institutionalized youths were the following:

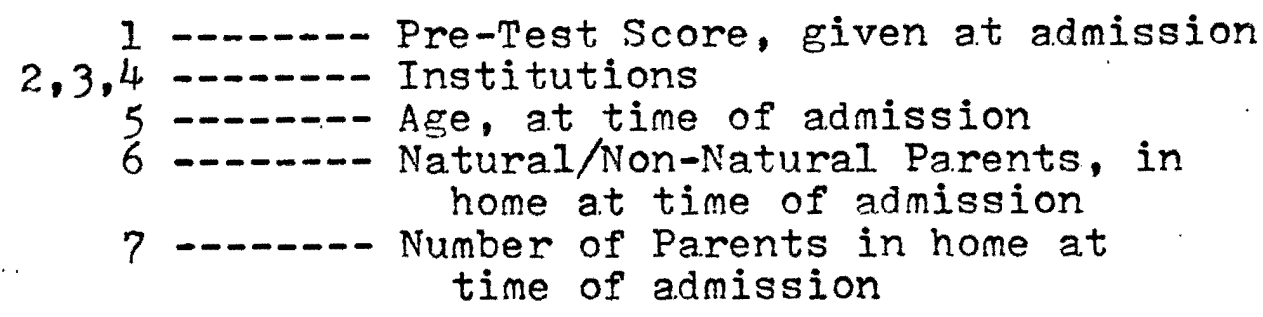

Time intervals for testing were the following:

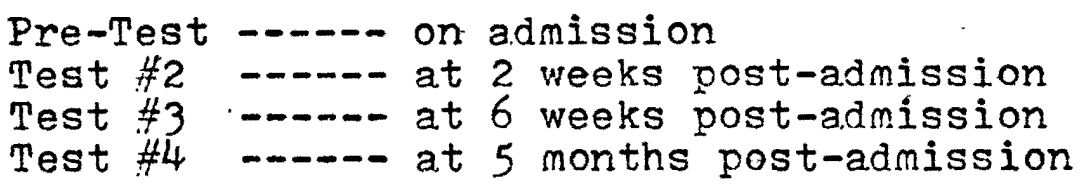

Collectively the seven factors of pre-test scores of institutionalized adolescents, participating institutions, age of * adolescents at the time of admission to institution, natural/nonnatural parents of youths at the time of admissions (variates $1,2,3,4,5,6,7$,$) had the following correlations with post-$ test scores: $63 \%$ at two weeks, $69 \%$ at six weeks and $53 \%$ at five months. (Table III) The relationships were significant on an $\mathrm{F}$ test at the $5 \%$ level of significance. (Table IV)

The combination of pre-score and the demographic factors (variates $1,5,6,7$, ) exercised a variability of $35 \%$ at two weeks, $32 \%$ at six weeks, and $16 \%$ at five months. (Table III) These were significance on an F test at the $5 \%$ level of significance. (Table IV) 
Institutions (variates $2,3,4$, ) with the effect of the other variables removed accounted for $28 \%$ of the variability at two weeks, $37 \%$ at six weeks and $37 \%$ at five months. (Table III) At two weeks the effect of institutions was not significant. At six weeks the factors became significant on an F test at the 5\% level of significance. Significance was maintained at five months. (Tabie IV) 
TABLE III

DISPLAY OF CHANGE IN THE CORRELATION $\left(R^{2}\right)$

OF VARIATE(S) TO POST-TEST SCORES

\begin{tabular}{|c|c|c|c|}
\hline Variate (s) & 2 Weeks & $\begin{array}{c}\text { Test Period } \\
6 \text { Weeks }\end{array}$ & 5 Months \\
\hline $1,2,3,4,5,6,7$ & $.63(63 \%)$ & $.69(69 \%)$ & $.53(53 \%)$ \\
\hline $1,5,6,7$ & $.35(35 \%)$ & $.32(32 \%)$ & $.16(16 \%)$ \\
\hline $2.3,4$ & $.28(28 \%)$ & $.37(37 \%)$ & $.37(37 \%)$ \\
\hline 1 & $.33(33 \%)$ & $.15(15 \%)$ & ---- \\
\hline 5 & $.01(1 \%)$ & $.11(11 \%)$ & $-\infty-\infty$ \\
\hline 6 & ------5 & $.04(4 \%)$ & $m--\infty$ \\
\hline$\overline{7}$ & ----- & $.07(7 \%)$ & $---m$ \\
\hline
\end{tabular}

\section{TABLE IV}

DISPIAY OF SIGNIFICANCE/NON-SIGNIFICANCE OF VARIATE(S)

\begin{tabular}{|c|c|c|c|}
\hline Variate(s) & $\begin{array}{c}2 \text { Weeks } \\
F\end{array}$ & $\begin{array}{c}\text { Test Period } \\
6 \text { Weeks } \\
F\end{array}$ & $\begin{array}{l}5 \text { Months } \\
\mathrm{F}\end{array}$ \\
\hline $1,2,3,4,5,6,7$ & $7.00 *$ & $7.47 *$ & $6.80 \%$ \\
\hline $1,5,6,7$ & $6.73 \%$ & $3.07 \%$ & $2.61^{*}$ \\
\hline $2,3,4$ & 2.71 & $8.43 \%$ & $4.20 *$ \\
\hline 1 & $12.79 *$ & $5.33 *$ & $-\cdots$ \\
\hline 6 & --- & 1.36 & --- \\
\hline$?$ & $-\cdots$ & 2.22 & $-\infty$ \\
\hline
\end{tabular}

* Significant on F test, derived from G. W. Snedecor and W. Cochran, Statistical Methods, Iowa. State University Press, 1967 Table A 14, pp. 560-503. See Analyzed Data, Appendix. 
The scores on the pre-test (variable 1) had the following correlations with post-test ratings: $33 \%$ at two weeks and $15 \%$ at six weeks. (Table III) The effect exerted by this variate was significant on an $\mathrm{F}$ test at the $5 \%$ level of significance. (Table IV)

Age (variate 5) occasioned the following variability with post-test scores: $1 \%$ at two weeks and $11 \%$ at six weeks. (Table III) The above was not significant on an F test. (Table IV) Institutional residents having natural/non-natural parents (variate 6) attributed a correlation with post-test scores of 4\% at the sixth week of testing. (Table III) This was not significant on an F test. (Table IV) $74 \%$ of these youths had natural parents at the time of admission, $26 \%$ had parents of some other classification, i.e., adoptive, foster, etc. (Table V)

\section{TABLE V}

COMPARISON OF NUMBERS OF INSTITUTIONALIZED ADOLESCENTS WITH NATURAL/NON-NATURAL PARENTS

\begin{tabular}{|c|c|c|}
\hline Parent (s) & Number & Percent \\
\hline $\begin{array}{l}\text { Natural } \\
\text { Parent }(s)\end{array}$ & 23 & $74 \%$ \\
\hline $\begin{array}{l}\text { Non-Natural } \\
\text { Parent(s) }\end{array}$ & 8 & $26 \%$ \\
\hline Total: & $3 I$ & $100 \%$ \\
\hline
\end{tabular}


Adolescents having one or both parents (variate 7) had a variability of $7 \%$ with post-test scores at six weeks. (Table III) This was not significant on an F test. (Table IV) $36 \%$ of the youths had one parent, $64 \%$ had both parents. (Table VI)

\section{TABLE VI}

COMPARISON OF NUMBERS OF INSTITUTIONALIZED ADOLESCENTS WTTH ONE OR BOTH PARENTS

\begin{tabular}{lcc}
\hline Parent(s) & Number & Percent \\
\hline $\begin{array}{l}\text { One } \\
\text { Parent }\end{array}$ & 11 & $36 \%$ \\
\hline $\begin{array}{l}\text { Both } \\
\text { Parents }\end{array}$ & 20 & $64 \%$ \\
\hline Total: & 31 & $100 \%$ \\
\hline
\end{tabular}

\section{Evaluation:}

From the data it is reasonable to conclude that a.1I the variables considered in this study exercised a significant and considerable influence on SDS Index scores for institutionalized adolescents after the initial testing. The combination of prescore and demographic elements was consistantly significant and served to validate these factors. Institutions account for a significant percentage of the effect on post-test scores after the second testing. Scores on the pre-test were significant in their influence on post-test scores through the five months of testing. It may be inferred that the lack of significance of 
this factor at two weeks was due to the youths not having been resident at the participating institutions long enough to make an appreciable impact on the test scores at this period. Age was not meaningful in terms of affecting SDS ratings in the post-test period. Data demonstrated that whether or not placed youths have biological parents or parents of some other classification bears little relation to post-test scores. The demographic factor of institutionalized adolescents having one or both parents was not a significant influence of test scores past the initial period of testing. As indicated, there was overall no significant change in the mean level of depression throughout the five months of testing. Thus, it is reasonable to state that no significant correlation exists between the above and demographic data. 


\section{CHAPTER V}

SUMMARY, CONCLUSTONS AND RECOMMENDATIONS

Although several interesting and possibly significant conclusions have been drawn from this study, the following qualifications should be considered:

First, the size of the sample of institutionalized youths, though large enough to be statistically significant, was a relatively small one. This was due to the fact that the number of new admissions over a certain time span was itself small. A more comprehensive study would have to allow for a. Ionger time span in order to obtain a larger sample via new admissions. This is especially true in the smaller treatment centers where there are only one or two adolescents entering each month. A larger sample might result in a wider variance of scores and might indicate some correlating factors which were not evident in this study.

Secondly, the size of the control group was small. As previously noted, the ten high school. students tested were not used as a control group for two reasons: (1) the size of the group was small, and (2) they were not tested longetudinarlly, as was the experimental groun, Rather, the group of high school students was tested because of our questions concerning where on the zung SDS the "normal" range of adolescents would fall. Third, the test itself may have been somewhat inappropriate for adolescents. Though it has been used by $Z$ ung with adolescents, it does appear from the study done by Mikesell 
and Calhoun and from our own testing of the ten "normal" students, that adolescents fall into a higher category on the index scale than do "normal" adults. However, this can be viewed as an expected occurrence, as the general range into which adolescents fall is that of transitory situational adjustment reactions. Authors we have reviewed indicate that adolescents are indeed in a transitory Ife, and one which tends to produce the same anxieties which are common to any transitory situation.

Whatever the reason for adolescents falling into this elevated category, it did present a problem of proper interpretation of SDS mean scores. The mean used for adults did not seem to apply to adolescents. We thus chose to use as meaningful a 10 point deviation from the mean score of the high school students, and from the initial test score. This has been explained in Chapter III.

The major conclusions with which we are concerned are those related to the four questions outlined in Chapter III. They are the following:

(1) Is the mean score for institutionalized youth significantly higher than for non-institutionalized youths? As seen in the data, the answer to this question is no. The mean score of the total test scores for institutionalized youths was not significantly different, higher or lower, from the mean score of ten high school students, nor from the mean score of adolescents tested in the study done by Mikesell and Calhoun. 
This clarifies two of the speculations made in Chapter I. First, that institutionalization per se does not cause depression. According to our data, youths who are institutionalized are no more likely to be depressed than youths who are not institutionalized. Second, we feel that it cannot be assumed that the acting-out behavior for which most youths are institutionalized is symptomatic of depression. Iiterature suggests that acting-out behavior (aggressiveness, out-of-control, runaway, delinquency, etc.) is the adolescents' symptomatic manifestation of depression. From the literature, it may therefore be speculated that the reason for which youths are institutionalized, their acting-out behavior, is actually depression. However, since our test group showed no higher depression ratings that the non-institutionalized, less acting-out youths, we cannot assume that their behavior is a mask for depression. Both of the above may have implication for the treatment approaches. That is, that depression may be considered an individual problem rather than an emotional state common to the majority of a population of a treatment center.

(2) Does the mean score of institutionalized youths increase with time in the institution, or does it decrease, or is there insignificant change? Looking at the total mean scores, there was no significant change in depression levels. However, in looking at Table III it should be noted. that there was significant change between the pre-test 
and the final test at Parrot Creek Ranch. The mean of the final scores was 18.2 points lower than the mean for the pre-test. Using the categories of the Zung index scale, this was not significant. However, using the 10 point variance mentioned, this was numerically significant. In other words, there appears to have been a decrease in depression level of youths who were in Parrot Creek Ranch, and the depression level at the end of a five month stay was lover than it was at the time of admission. This steady decrease did not occur in the youths tested at the other three treatment centers. It is not within the scope of this study to speculate on why a decrease occurred at only Parrot Creek Ranch.

(3) If there is a change in the depression level does it correlate significantly with any of the demographic data? Since there was no significant change in depression level there can be no correlation between that and any demographic data.

(4) Observations will be made of the pre-test scores of youths who ran away from the treatment centers. Only two youths ran away from the centers, and observations of these two pretest scores indicate nothing significant.

Our statistical analysis of the variance of the test scores yielded some interesting results. As shown on Table IV, 63\% of the variance could be accounted for at two weeks; $69 \%$ at six weeks; and $53 \%$ at five months.

The variables of most interest to us are the institutions. With the effect of the other variables removed, institutions ac- 
counted for $28 \%$ at two weeks, $37 \%$ at six weeks, and $37 \%$ at five months. We did not consider the $28 \%$ at two weeks to be significant because of the short time the adolescents had been at the institutions. However, the $37 \%$ at both the six week and five month test periods is significant. This indicates to us that the effect of institutionalization has a definite impact upon the intermal depressive condition of the adolescent. Another variable which should be mentioned is that of the pre-test. The statistical analysis indicated a positive correlation between the pre-test and subsequent tests. In other words, if a subject scored high on the pre-test, he was inclined to continue this pattern on later tests. Likewise, if a subject scores low on the pre-test, he was inclined to have a low score on subsequent tests.

The remaining variates (age, natural/non-natural parents. number of parents) when taken individually were not significant. Considered collectively, they were significant at the two week and six week testings. However, at these times they were shown to be less significant than the institutions in their impact. This leads us to conclude that it is not necessarily the internal depressive condition of individual, or what environmental condition they have come from that determines their level of depression; rather the level of depression is more likely to be determined by the process of institutionalization. 


\section{Implications for Further Study}

As mentioned before, the sample group size was small. If further study were done, it would be more significant if this group were larger, and if it also were more of a crosssection of institutionalized population. For example, our sample of the smaller, mural treatment centers was an all-imale sample. It would enhance validity if some female populations of smaller treatment centers be studied as well, along with males and females of the larger centers. Further study may also attempt to include a cross-representation of different cultures and races.

The control group would be more significant first if it were larger, and secondly, if it were tested over the same time span as the experimental group. Changes in the degree of depression could relate to seasonal changes, or other time factors, and longetudinal testing of a control group would point that out. The control group should also be a larger crossrepresentation of the adolescent population.

Since the data in this study indicates that the variance in depression scores is affected significantly by the institutionalization, it would be interesting to study the characteristics of various institutions to determine what has the most effect on depression. Such a study could take into account the size of the institution, its policies, its staff, its treatment approaches, and its physical atmosphere, and determine if these correlate with depression. 
Whatever further study is done on adolescent depression, especially as it relates to institutionalization, would be of interest, as there appears to be little research done in this field. Considering the emotional turmail characteristic of teen-age years, it would seem important that the subject of adolescent depression be given more study and consideration. 
VARIATES - $1,2,3,4,5,6, ?$

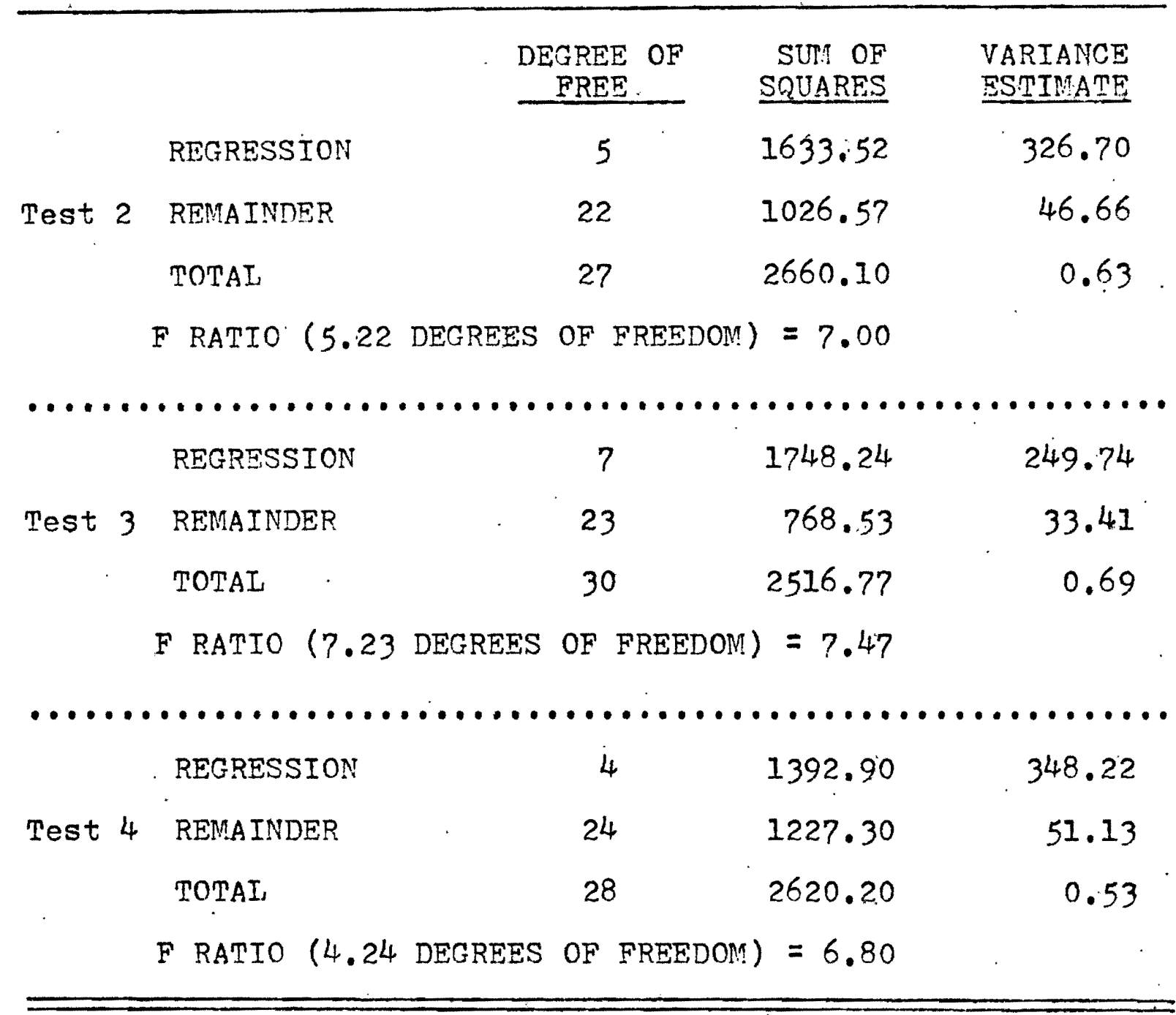

VARIATES $-1,5,6,7$

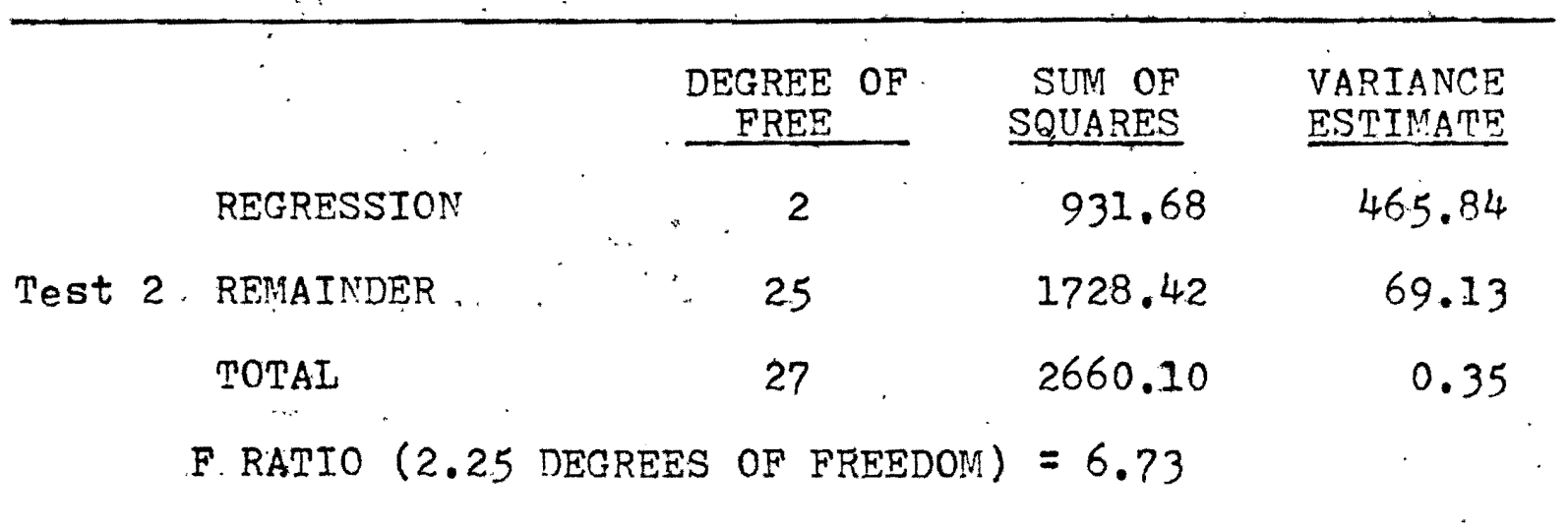




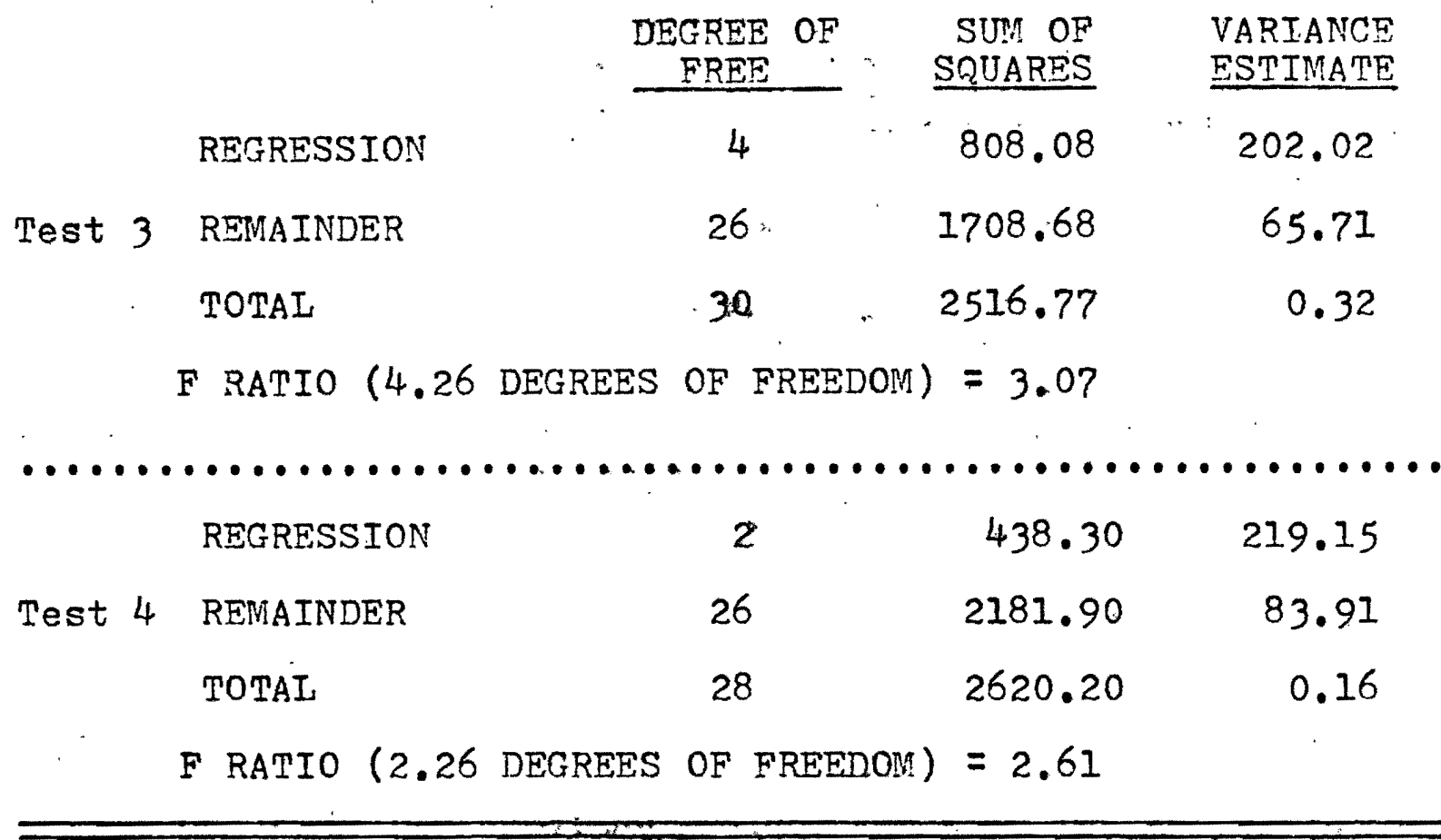

VARIATES $2,3,4$

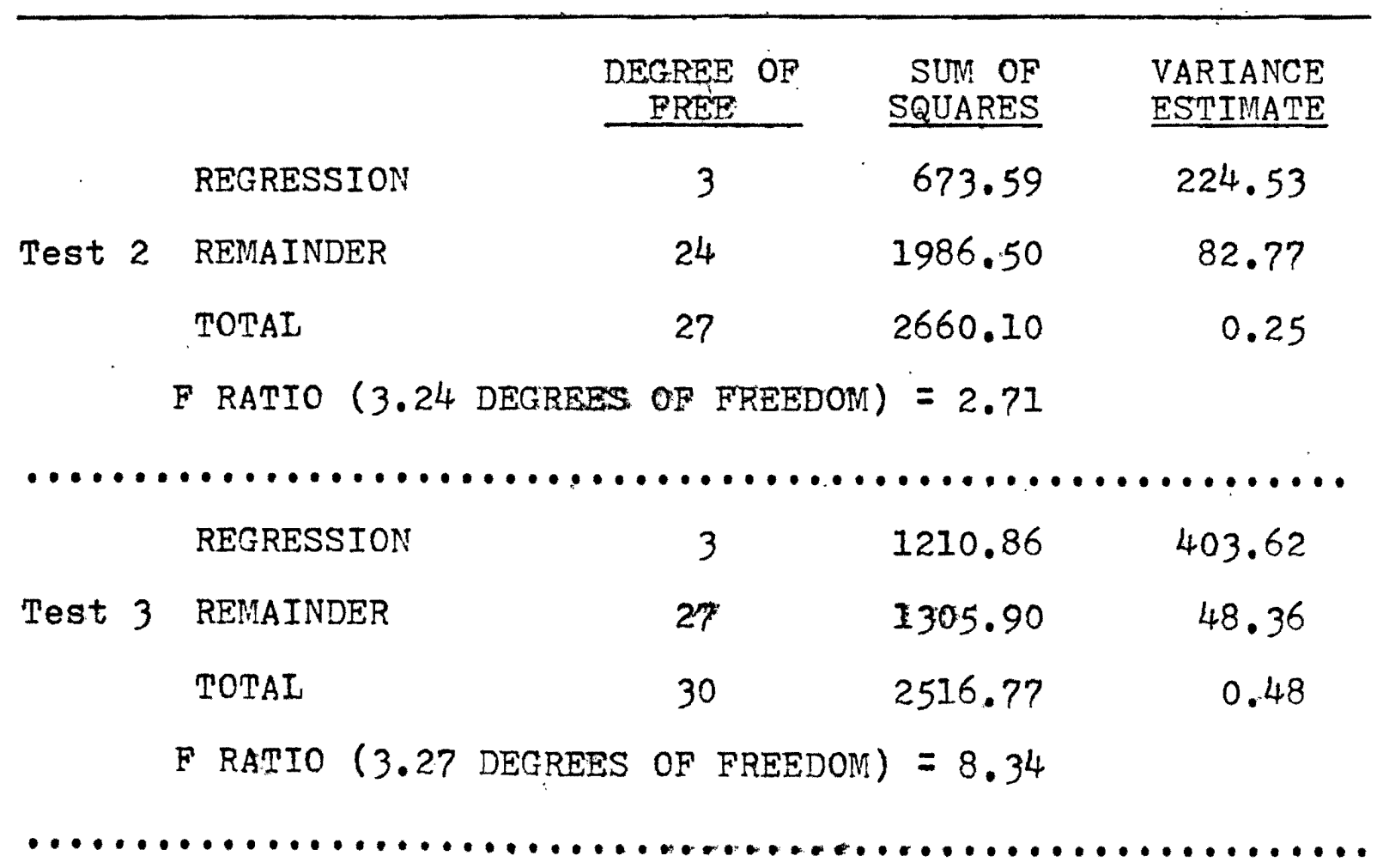




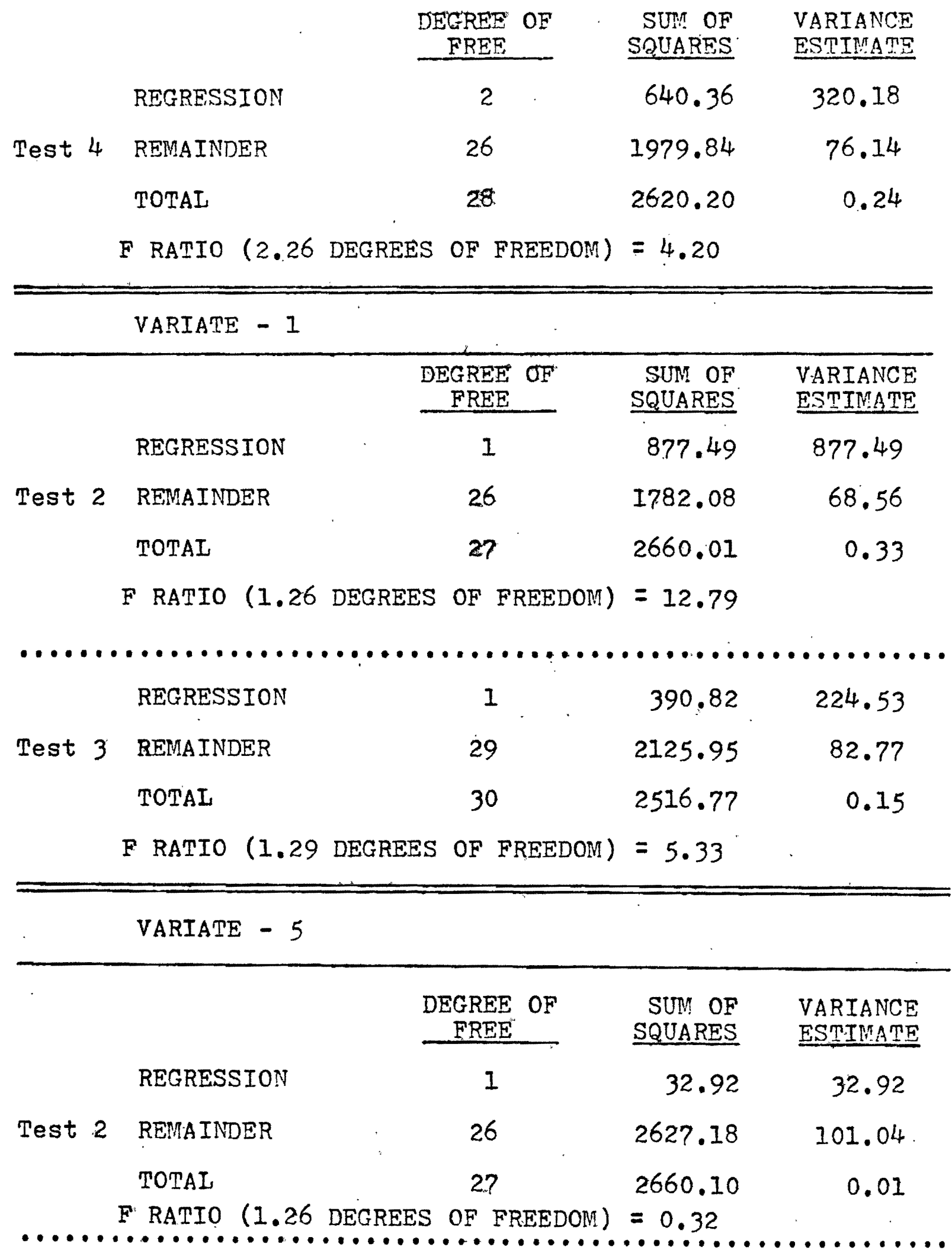




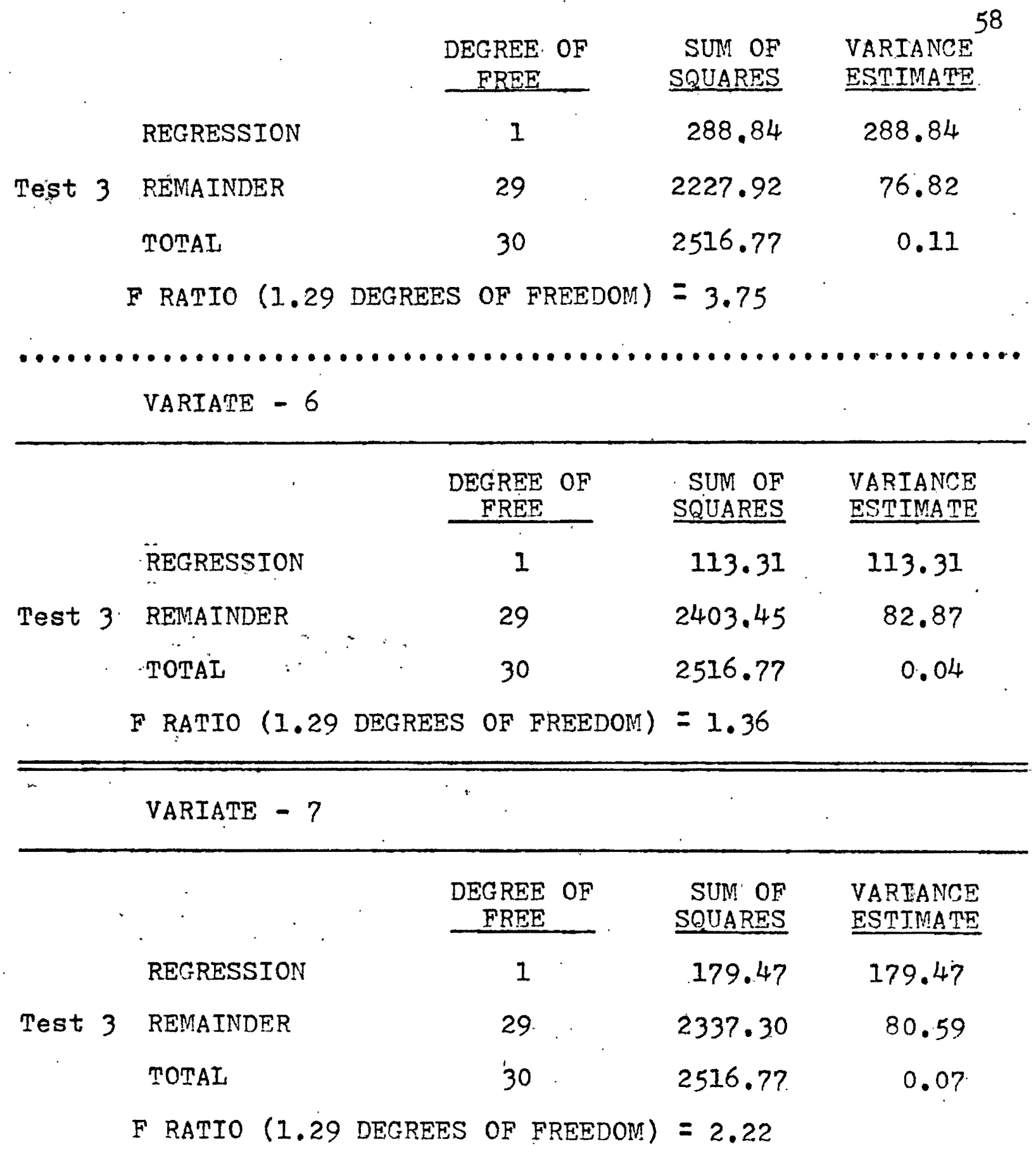




\section{BIBLIOCRAPHY}

Abraham, Karl. 1953, "Notes on the Psychoanalytic Investigation and Trea.tment of Manic-Depressives, Insanities, and Allied Conditions". Selected Papers on Psvchoanalysis, 340-357.

Barter, J. Swaback, D. Todd, J. 1968, "Adolescent Suicide fttempts", Archives of General Psychiatry, 19:523-527.

Beck, A. 1967, Depression: Clinical, Experimental and Theoretical Aspects.

Bemporad, J. 1971, "New Views on the Psychodynamics of the Depressive Character," The Horld Biennial of Psychiatry and Psychotherapy, 130-138.

Bibring, E. 1953, "The Mechanism of Depression," Affective Disorders, $2: 13-48$.

Binger, C. 1961, "Emotional Disturbances Among College Women," Emotional Problems of the Student, Ed. G. Blaine, 170180.

Brown, F. 1961, "Depression and "Childhood Bereavement," Journal of Mental Science, 107:754-777.

Brown, G. Zung, M. 1972, "Depression Scales - Self-Rating or Physician Rating Validation of Certain Clinically observable Phenomena," Journal of Clinical Pharmasychiatry, $12: 360-366$.

Burks, H. Harrison, S. 1962, "Aggressive Behavior as a Means of Avoiding Depression," American Joumal of Orthopsychiatry, 7:415-424.

Cantor, 1962, "Adolescent Suicide," Time, 99:57-59.

Carrol, B. Fielding, J. Blashke, T. 1973, "Depression Rating Scales; Critical Review," Archives of Gen. Psychiatry, $28: 360-371$.

Chien, C. Kaplan, R. 1971, "Clinical Trial of Imidazolina as an Anti-Depressant," Current Therapy Review, 13:350-352.

Chwast, J. 1967, "Depressive Reactions as Manifested Among Adolescent Delinquents," American Joumal of Psychotherapy, $21: 575-584$. 
Draper, N. Smith, H. Applied Regression Analysis, John Wiley and Sons, Inc., New York, 1967.

Elkind, 1972, "Anatomy of Melancholy," Saturday Review, 55: 54-59.

Elson, M. 1964, The Reactive Impact of Adolescent and Family Upon Each Other in Separation," Journal of the Am. ACademy of Child Psychiatry, 3:697-708.

Fenichel, 1968, The Meaning of Despair, Ed. Gaylin.

Freeman, L. 1969, The Cry for Love.

Frued, A. Jacobsen, E. 1961, "Adolescent Moods and the Remodeling of Psychic Structures in Adolescence," Psychoanalytic study of the Child, 16:164-183.

Freud, A. 1958, "Adolescence," Psychoanalytic Study of the Child; $13 ; 255-278$.

Freud, S. 1957, Mourning and Melancholia," Standard Edition, $X I V ; 243-258$.

Gianturco, J. Zung, W. 1971." "Personality Dimension and the Self-Rating Depression Scale," Jour. of Clinical Psychology, $12,243-249$.

Gould, R. 1965, "Suicide Problems in Children and Adolescents," Am. Jour. of Psychotherapy, 13:226-232.

Jacobs, J. Teicher, J. 1967, "Broken Homes and Social Isolation in Attempted Suicides of Adolescents," Internationa.1 Joumal of Social Psychiatry, 13:139-149.

Keeler, W. Shore, S. Speed, I. 1954, "Childrens Reaction to the Death of a Rarent," Depression, Ed. P. Hoch, 108-125.

Kellner, R. Sheffiel, B. 1973, "Self-Rating Scale of Distress," Psychological Med., 3;88-100.

Laufer, M. 1967, "Assessment of Adolescent Disturbances," Psychoanalytic Study of the Child, 20;99-123.

Laufer, M. 1966, "Object Loss and Mourning During Adolescence," Psychoanalytic Study of the Child, 16:164-183.

Lonrad, S. 1967, "Adolescent Depression," International Jour. of Psychoanalysis, $48: 53-60$. 
Marone, J. Iubin, B. 1968, "Relationship Between the Depression Adjective Checklists and Zung SDS," Psychological Abstracts, $22 ; 330-335$.

Masterson, J. Tucher, K. Berk, G. 1963, "Psychopathology in Adolescence; Ciinical and Dynamic Characteristics," Am. Jour. of Psychiatry, 120;35?-366.

Meeks, John, 1971, The Fragile Alliance.

Mendels, J. Weinstein, C. 1972, "Relationship Between Depression and Anxiety," Archiv, of Gen. Psychiatry, 14;657660 .

Mikesell, R. Calhoun, I. 1970,"Faking on the Zung SDS" Psychological Report, 9;173-174.

Mikesell, R. Calhoun, I. 1970, "Response Set on the SDS," Perceptual and Motor Skilis, 30,18-24.

Ostrow, M. 1970, The Psychology of Melancholy.

Rado, Sandor. 1968, The Meaning of Despair, Ed. Gaylin, 170185.

Root, N. 1958, "A Neurosis in Adolescence," Psychoanalvtic study of the child, $13: 320-334$.

Sabbath, J. 1969, "The Suicidal Adolescent, The Expendable Child," Journal of Am. Academy of Child Psychology, $8 ; 272-289$.

Schwab, T. 1968, "Sex and Age Differences in Depression in Medical Inpatients," Mental Hygiene, 52;627-630.

Shainberg, D. 1966, "Personality Restrictions in Adolescence," Psychiatric Quarterly, $14 ; 390-400$.

Silverman, C. 1968, "The Epidemiology of Depression."

Snedecor, G. W. Cochran, W. Statistical Methods, Iowa State University Press, 1967.

Spector, S. 1967, "The Problem Adolescent," Adolescence, II; $7-13$.

Stanley, E. Barter, J. 1970, "Adolescent Suicidal Behavior," Am. Journal of Orthopsychiatry, 40;89-96. 
Swanson, B. Anderson, C. "Fraking on the Zung Self-Rating Depression Scale - Replication and Refinement," Journal of Clinical Psychology, 28;193-196.

Zung, W. 1965, "A Self-Rating Depression Scale," Arch. of General Psychiatry, 12;60-73.

Zung, w. 1969, "A Cross Survey of Symptoms in Depression," Am. Jour, of Psychotogy, 126;100-131.

Zung, W. 1968, "Evaluating Treatment Methods for Depressive Disorders," Am. Jour. of Psychology, 124:40-59.

Zung, w. 1967, "Factors Thfluencing the Self-Rating Depression Scale," Archives of General Psychiatry, 16:530-573.

Zung, W. 1972, "How Normal is Depression?" Psychosomatics, $13: 174-178$.

Zung, W. 1965, "Self-Rating. Depression Scale in an Outpatient ciinic," Archives of GeneraI Psychiatry, 13:504-529.

Zung, W. 1972, "The Depression Status Inventory; An adjunct to the Self-Rating Depression Scale," Joumal of Clinical Psvcholosy, 28;539-543.

Zung, W. 19?1, "The Differentiation of Anxiety and Depressive Disorders; A Biometric Approzck," Psychosomatics, 380384. 